\title{
Age Related Cognitive Impairments and Diffusion of Assistive Web-Base Technologies
}

\author{
Senaka Fernando, Tony Elliman, Arthur Money, and Lorna Lines \\ The School of Information Systems, Computing and Mathematics, Brunel University, \\ Middlesex, UB8 3PH, UK \\ \{senaka.fernando, tony.elliman, Arthur.money, \\ lorna.lines\} abrunel.ac.uk
}

\begin{abstract}
Several researchers argue that age related cognitive impairments have detrimental affect on use of web services by older adults. However little and systematic applied research has been conducted on how age related cognitive impairments might affect the usage of web services by older adults. Undoubtedly, understanding the relationship between the cognitive changes that accompany aging and their impact on older adults' usage of web services will be beneficial for designing web services for this group. The paper demonstrates how such understanding has been employed to develop an assistive technology in order to improve older adults' interaction with online forms (e.g. state benefit application form). However the paper acknowledges that this new assistive technology does not guarantee that people with age related cognitive impairments accept it, as diffusion of innovation research shows that getting a new technology adopted even when it has noticeable advantage is often very difficult. Consequently the paper identifies critical factors that need to be considered when adopting this new assistive technology, drawing on Rogers (2003) theory of Diffusion of Innovations.
\end{abstract}

Keywords: age related cognitive impairments, older adults, assistive technology, online forms and web services, innovation, diffusion.

\section{Introduction}

Recent surveys show that the number of people over the age of 65 is increasing worldwide. For example by 2030, the percentage of people over the age 65 in Europe will be about $24 \%$ of the total population [1]. However research indicates that the growing numbers of these older adults are living in their homes with limitations in mobility, dexterity, and cognitive ability[2]. Currently there is considerable discussion about the scope of improving the older adults' autonomy and independence that is restricted by age related impairments, using recent developments in information technology[3]. One of such development is web services and it is rapidly becoming a major means of accessing health, care in the community and many government services for the older adults[4]. The web services are also becoming a vehicle for older adults in engaging activities such as employment and educational opportunities[5]. However the older adults use web services less often and have less experience with them than 
younger adults. For example the recent surveys show that web service users among those 16-24 years of age are three times higher than among adults 55-74 of age[see 5].

Although there are many reasons for the lack of use of web services by older adults, one major reason noted in the literate is the age related impairments which hinder the visual, auditory, motor and cognitive abilities of older adults[6]. The research indicates that such impairments have detrimental affect on use of web services by older adults. Many researchers and practitioners made attempt to address the implications of age related visual, auditory and motor impairments that have impact on information technology based systems and developed technology to minimise the negative impact of such impairments on usage of such systems by older adults[see 7 , 8]. However little research has been conducted on how age related cognitive impairment might affect the usage of information technology based systems such as web services[see 9]. Consequently this paper focus on age related cognitive impairments.

With reference to the age related cognitive impairments the paper discusses the implications of impairments in working memory, spatial cognition, attention and perceptual speed on usage of web services by older adults. These impairments are briefly discussed below:

Working memory. Working memory is usually conceptualized as "the temporary storage of information that is necessary for such activities as learning, reasoning, and comprehension"[10]. The usual tasks carried out by working memory are those in which the individual must hold a small amount of material in mind for a short period of time while at the same time performing further cognitive operations (e.g. comprehension), either on the material held or on other incoming materials [11]. The decline of working memory holds a number of implications for the use of web services/applications by older adults. For example older adults can have difficulties in (1) understanding instructions in an online form (2) performing a large number of steps in an online transaction.

Perceptual speed. The age related cognitive impairment make older adults to have a general slowing of perceptual and motor processes involved in perceiving and responding to items. In other words the perceptual speed (the speed at which mental operations are performed) is decreased with increased age. Such slowness is raised, when task complexity increases. As a result older adults have difficulties performing complex tasks on websites which must be done externally imposed time constraints [see 12]. For example older adults may take considerable time to submit an online form after completing it.

Spatial abilities. Spatial ability refers to skill in perceiving the visual world, transforming and modifying initial perceptions, and mentally recreating spatial aspects of one's visual experience. [13]. Spatial abilities boost during adolescence, reach their height during the second or third decade of life, and shrink steadily thereafter. Thus older adults have lower levels of abilities in performing tasks which require spatial visualisations, integration of spatial information, and ongoing information processing [14]. As many websites have complex computer screens which contains complex menu structures, banners, animations, three dimensional presentations etc which demands high degree of spatial abilities, older adults will have difficulties in using 
existing websites [see 15]. For example older adults may have difficulties in understanding how to move to next page when next page button is available on an online form.

Attention. Attention refers to the process which enable individual to allocate cognitive resources when two or more distinct cognitive tasks[16]. As existing web pages present scenarios where users require doing more than one thing at time older adults who have impaired attention will have difficulties in using them.

Although there is very little research was conducted on implications of age related cognitive impairments on usage of web services/applications by older adults, some research demonstrate that the difficulties that older adults having when using web services, can be mediated by the manner in which web services are designed. Such research demonstrates that designing web services that take into consider age related cognitive impairments would consequently enhance the usage of web services and other computer applications by older adults [17, 18]. For example Holt and Morrell[17] demonstrate that efficiency of text comprehension by older adults is improved when the text is well organised and clearly presented in short segments on web pages.

\section{The Project}

The project, Delivering Inclusive Access to Disabled and Elderly Members of the community (DIADEM), used systematic effort to understand older adults' needs related to web services that are shaped by their declined cognitive impairments and incorporate them into design solutions. DIADEM project is developing an assistive technology to help the older adults with age related cognitive impairments, to use the web services more effectively. The project focuses on the problem of accessing services online where older adult users need to fill in online forms (e.g. housing benefits applications). The DIADEM is currently being undertaken in the UK, Norway and Italy and funded by the European Union (EU). The following EU project partners are involved in the project:

1.Brunel University (Brunel) in the UK

2.Norsk Regnesentral (NR) in Norway

3.Bluegarden (BG) in Norway

4.More Optimised Registration Elements(More) in Norway

5.CSI Piemonte (CSI) in Italy

6.Sheffield City Council (Sheffield) in the UK

7.Comune di Torino (Torino) in Italy

\section{Methodology}

The methodology consists the key stakeholder focus group interviews, the older adult user interviews and the older adult user trials. Key-stakeholders comprised not only the developers and the service providers but also representatives from government agencies, private care/medical agencies and charities that support the older adults in each partner country (the UK, Norway and Italy). From the analysis of the key 
stakeholder focus group and the older adult user interviews, core functional and usability requirements was identified for all applications as they are presented and accessed through DIADEM. The software specification is the main output from the gathering and analysis of the functional and usability requirements. The main focus of this software specification was a description of what all the functions of the software of the DIADEM are. These were defined in grate length to ensure that the developers understand what the older adult users require from the DIADEM and prioritise the requirements to pay considerable attention to the items that were perceived by the older adult users as very important. The DIADEM technology was developed using these specifications. The older user trials were employed to evaluate the efficiency, effectiveness, usability of the technology developed and the older users' satisfaction with it. Using the various results from these older user trials the DIADEM technology is being further improved

\section{The DIADEM Technology}

To respond to the challenges faced by older adults with age related cognitive impairments DIADEM employs Expert System techniques to analyse user behaviour and adapt the presentation of the transaction dialogue to mitigate the cognitive problems exhibited by the user. To ensure that a single user sees every online form in a consistent and personalised style this client component is data driven. It takes XML control files, which contain an abstract transaction description from the server, and generates an appropriate user interface using a rich set of multimedia devices (e.g. sound, video, document scanning and smart cards) to reduce the cognitive load on the user.

All user interaction with DIADEM takes place through a web browser. DIADEM is responsible for providing immediate help functionality in a consistent way across all services. In addition, if the DIADEM system fails to provide adequate "on screen" assistance it has access to external means of help desk support.

To respond to the security and trust issues around user identification and profiles DIADEM allows the end-user's computer to have a facility for user authentication that is not password-based (e.g., fingerprint, retina, smartcard, signature recognition). The DIADEM system keeps all user profiles confidential from other parties other than their respective users. It also protects the integrity of all user profiles so that the profile can only be modified by the system or by an authorised individual.

\section{Diffusion of Assistive Technology}

All the characteristics mentioned in section 4 will reduce the impact of age related cognitive impairments on usage of web services by older adults. However, as this assistive technology has never been seen before, there will be inherent uncertainty to this untested innovation. Rogers[19] argues that getting a new innovation adopted even when it has noticeably advantages, is often not easy as the decision to adopt an innovation take time. As a result, during the project the partners of the projects (the research teams) will have the responsibility of determining how best to progress the DIADEM technology to form the basis of future commercial products. For example 
MORE intends to adopt DIADEM technology in their forms based informationcapture services for public authorities (both local and central) and financial institutions. Similarly, Bluegarden intends to adopt the same technology in their HR-services for the employees of large companies in Norway and Denmark. Also, CSI, Sheffield, and Torino all anticipate being able to adopt DIADEM technology for their current public service provisions. These commitments are to exploit this technology, subject to business environment and market conditions, as a matter of urgency as soon as practically possible either within the project timeframe or after it. All these activities will be major components of the diffusion of DIADEM technology.

According to Rogers (2003), the diffusion of innovations is "the process by which an innovation is communicated through certain channels over time among the members of a social system." Innovation is used more generally here to mean an item, thought, or process that is new and diffusion is the process by which innovations spread one social group to another. Diffusion of innovation theory suggests that consumers of new technology make their adoption decisions base on several factors [20].

Relative advantage: The benefits of adopting the new technology compared to the cost.

Compatibility: The extent to which adopting and using the innovation is based on existing ways of doing things and standards cultural norms.

Complexity: How difficult the new product is.

Trialability: The extent to which a new product can be tried on a limited basis.

Ability to communicate product benefits: The ease and clarity with which the benefits of owning and using the new product can be communicated to prospective customers.

Observability: How observable the benefits are to the customer using the new product, and how easily other customers can observe the benefits being received by a customer who has already adopted the product.

Each factor affects the rate of adoption of a innovation differently. However, empirical evidence suggests that relative advantage is consistently the best forecaster of adoption of new technology [21-23]. Consequently, the key issue related to diffusion of DIADEM technology is to assess the relative advantage that DIADEM technology brings to application and service providers. The perceived advantages of adopting DIADEM, when weighed against the associated costs and risks, need to justify a provider in adopting DIADEM technology as one of their service delivery channels. The questions need to be addressed in this context are discussed in more detail below.

Does DIADEM demonstrate advantages for an application provider? This question goes to the issue of assessing the benefits of DIADEM from a provider's perspective. It is accepted that direct cash flow benefits are hard to quantify and the innovators are expected to address this question from a broader qualitative standpoint rather than a strictly financial one.

One such approach to evaluating technology adoption is to consider the observability or awareness of advantages to various stakeholders. The premise here is that the more clearly observable the benefits then the greater the likelihood of technology adoption. In the first instance there is the need to consider how observable the benefits are to an elderly person using DIADEM to access online services. Second is the 
question of how easily an application or service provider can observe such benefits being transferred or translated into benefits for them.

Is the effort required to adopt DIADEM technology reasonable? The effort required to adopt DIADEM technology goes to the other side of the relative advantage equation. Since technological complexity is a barrier to adoption it is necessary to consider the perceived simplicity of adopting and using DIADEM. From the provider's perspective this amounts to the simplicity of creating and maintaining the interface between their information systems and the DIADEM software. However, for success the technology also needs to be adopted by the elderly user group and it is also necessary to consider whether they will find difficulties in using DIADEM. In so far as the technology does present complex characteristics they need to be demonstrable as absolutely necessary, in terms of the elderly users' requirements.

However, the adoption effort required will also vary from one application or service provider to another depending on DIADEMs compatibility with their existing provision. This raises the question of the extent to which providers may have to learn new skills, gain new knowledge and make change in their existing way of working to enable their legacy systems to use DIADEM software.

Is the business model and licensing appropriate? The other main element on the down side of the relative advantage equation is the market or business model and the availability of appropriate software licences. In addition to the direct cost of licensing providers need to minimise the risks they take when adopting a new technology. Critical risk factors are first the existence of an adequate "market demand" and second the ability to control the initial take up costs.

The DIADEM supplier's ability to communicate product benefits positively influences market demand and reduces the risk of an inadequate return on investment for the application or service provider. Consequently there is the need to evaluate whether the project partners effectively convey the benefits of DIADEM to the market place in such a way as to generate a reasonable demand for the technology.

Minimising the risk of incurring significant take-up costs depends upon the extent to which DIADEM can be tried on a limited basis. This is a major issue with new technological products or innovations that might at first be perceived as complex and incompatible with existing technologies. Thus, there is the need to evaluate whether the business model and licensing makes it feasible for application and service providers to try DIADEM on a limited basis prior to making a long term commitment.

\section{Conclusion}

The paper present that how age related cognitive impairments would affect the use of web services by older adults. It emphasis that developers and providers of web services need to have significant understanding of the impact of age related cognitive impairment on usage of web services. The paper demonstrates how such understanding has been employed to develop an assistive technology in order to provide an adaptable web browser for the older adults with age related cognitive impairments to improve their interaction with web base forms. This improvement is achieved by developing an Expert System, which monitors the user's behaviour to adapt and personalise the computer interface as the user interacts with web based forms whilst 
providing privacy and security. Drawing on Diffusion of innovation theory the paper suggests that several factors need to be considered when adopting this new technology. It argues that major factor that influences the process of adoption is relative advantage. The papers shows that detail understanding of these factors would help innovators of the DIADEM to assess (1) how quickly the DIADEM might take off in the unconventional marketplace (2) critical barriers to commercialisation and diffusion of the DIADEM. Such assessment would help the innovators of the DIADEM and similar technologies to develop effective marketing strategies to improve the commercialisation and diffusion of such technologies.

However diffusion arenas of assistive technologies such as DIADEM are highly complicated. The institutional (e.g. governments) policies and practices would shape in defining the scope and authorization for the diffusion process of these technologies. For example governments' social policies related to elderly and their political commitments to improve the quality of life of elderly can radically affect the diffusion process. Nevertheless diffusion of innovation theory does not seem to offer adequate knowledge to deal with highly complex political and institutional issues in diffusion arenas. Consequently future research on assertive technologies such as DIADEM would be much more effective if they extend their studies combining the diffusion of innovation theory with other theoretical perspectives that can be employed to address such issues in diffusion arenas.

Acknowledgements. The authors wish to acknowledge the European Union funding of DIADEM as a Framework 6 project (034106). They also wish to acknowledge the contributions of the other DIADEM consortium members - Norsk Regnesentral (Norway), Bluegarden AS (Norway), More Optimised Registration Elements AS (Norway), CSI-Piemonte (Italy) Sheffield City Council (UK), and Citta di Torino (Italy) - in supporting this research.

\section{References}

1. Kinsella, K.: An Aging World. US Government Printing Office, Washington (2001)

2. Grundy, E.: The epidemiology of aging. In: Tallis, R.C., Fillit, H.M. (eds.) Brocklehurst's Textbook of Geriatric Medicine and Gerontology, pp. 3-20. Churchill Livingstone, Edinburgh (2003)

3. McMellon, C.A., Schiffman, L.G.: Cybersenior Empowerment: How some older inviduals are taking control of their lives. The Journal of Applied Gerontology 21(2), 157-175 (2002)

4. Morrel, R.W., Mayhorn, C.B., Bennett, J.: A survey of World Wide Web in Middle Age and Older Adults. Human Factors 42(2), 175-185 (2000)

5. Czaja, S.J., Lee, C.C.: The impact of aging on access to technology. Universal Access in the Information Society (5), 341-349 (2007)

6. Czaja, S.J., Lee, C.C.: Information systems and older adults. In: Sears, A., Jacko, J.A. (eds.) The Human Computer Interaction Handbook, pp. 777-792. Lawrence Erlbaum Associate, London (2008)

7. Fisk, A.D., et al.: Designing for older adults; Principles and creative human factors approaches. Taylor and Francis, London (2004) 
8. Smith, N.W., Sharit, J., Czaja, S.J.: Aging, motor control and performance of computer mouse tasks. Human Factors 41(3), 389-396 (1999)

9. Czaja, S.J., et al.: Factors predicting the use of technology: Finding from the centre for research and education on aging and technology enhancement. Psychology and Aging 21(2), 333-352 (2006)

10. Bradeley, A.D.: Working Memory. Oxford Scientific Publications, Oxford (1986)

11. Morris, R.G., Craik, F.I.M., Gick, M.L.: Age difference in working memory tasks. The role of secondray memory and the central executive system. Quarterly Journal of Experimental Psychology 42A, 67-86 (1990)

12. Newell, A.F., et al.: Information technology for cognitive support. In: Sears, A., Jacko, J.A. (eds.) The Human Computer Interaction Handbook, pp. 811-828. Lawrence Erlbaum Associate, London (2008)

13. Howard, G.: Frames of mind: The theory of multiple intelligences. Basic Books, New York (1985)

14. Morrell, R.W., Echt, K.V.: Instructional design for older computer users: The influence of cognitive factors. In: Rogers, W.A., Fisk, A.D., Walker, N. (eds.) Aging and skilled performance, pp. 241-265. Lawrence Erlbaum Associate, New Jersey (1996)

15. Kurniawan, S.H., et al.: Personalising web page presentation for older people. Interacting with Computers 18, 457-477 (2006)

16. Gross, R.: Psychology: The science of mind and behaviour. Hodder and Stoughton Educational, London (2001)

17. Holt, B.J., Morrell, R.W.: Guidelines for web site design for older adults: The ultimate influence of cognitive factors. In: Older Adults, Health Information, World Wide Web, pp. 109-129. Lawrence Erlbaum Associate, London (2002)

18. Sharit, J., et al.: The effect of age and environmental support in using telephone voice menu systems. Human Factors 41(3), 389-396 (2003)

19. Rogers, E.: Diffusion of Innovation, p. 512. Simon and Schuster International, New York (2003)

20. Mohr, J., Sengupta, S., Slater, S.: Marketing of High-Technology Products and Innovation. Pearson Education, New Jersey (2005)

21. Choudhury, V., Karahanna, E.: The Relative Advantage of Electronic Channnels: A Multidimensional View. MIS Quarterly 32(1), 179-200 (2008)

22. Moore, G., Benbasat, I.: Development of an Instrument to measure the perceptions of adopting information technology innovation. Information Systems Research 2, 192-222 (1991)

23. Plouffe, C., Hulland, J., Vandenbosch, M.: Research Report: Richness verses parsimony in modelling technology adoption decisions-Understanding merchant adoption of a smart card-based payment systems. Information Systems Research 12, 208-222 (2002) 